Title: Demand Management to Mitigate Impacts of Plug-in Electric Vehicle Fast Charge in Buildings WITH RENEWABLES

CORRESPONDING AUTHOR:

FAKEHA SEHAR

EMAIL ADDRESS: SEHAF0@VT.EDU

CONTACT NO.: +1 (571) 241-2846

FAX NO.: +1 (571) 858-3315

(C) 2017. This manuscript version is made available under the Elsevier user license http://www.elsevier.com/open-access/userlicense/1.0/ 


\title{
Demand Management to Mitigate Impacts of Plug-in Electric Vehicle Fast Charge in Buildings with Renewables
}

\author{
Fakeha Sehar ${ }^{\text {a }}$, Manisa Pipattanasomporn ${ }^{\text {a }}$ and Saifur Rahman ${ }^{\text {a }}$
}

${ }^{\mathrm{a}}$ Virginia Tech-Advanced Research Institute, Arlington, VA, 22203 USA

\begin{abstract}
Plug-in electric vehicle penetration is increasing due to technical advancements and environmental concerns. Along with residential plug-in electric vehicle charging, the public charging infrastructure is much needed to reduce plug-in electric vehicles' range anxiety and foster their adoption. Renewable energy and demand management programs are considered viable options that can reduce the impacts of widespread plug-in electric vehicle penetration on the electric grid. This research studies the impacts of plug-in electric vehicle direct current fast charging on a simulated standalone retail building's peak demand and energy consumption, and presents the ability of renewable energy and demand management options to reduce their impacts. Additionally, insights into a public charge station usage are presented by monitoring different types of plug-in electric vehicle charge behaviors at a retail site. Research findings indicate that demand management of building end-use loads along with the use of solar photovoltaic can contribute to absorbing plug-in electric vehicle penetration at the building level ranging from the average of $7 \%$ for the demand management option alone to an average of $38 \%$ for the combination of demand management and solar photovoltaic, and contributing to shifting building peak demand to late evening hours.
\end{abstract}

Keywords

Plug-in Electric Vehicles; Photovoltaic; Retail Building; Demand Management; Direct Current Fast Charging

\section{Introduction}

Plug-in Electric Vehicles (PEVs) will play a key role in the U.S. transportation future as they reduce petroleum dependence and greenhouse gas emissions [1]. However, there are some barriers to PEV adoption, including PEV cost, range anxiety and availability of charging infrastructure [2]. With growing PEV penetration, public charging infrastructures coupled with fast charging would be needed. Depending on PEV penetration, PEV can result in negative impacts on an electrical grid [3]. As opposed to Level 1 charging (rated at 120V [4]), Level 2 charging (rated at 208/240V [4]) can quickly increase peak electrical demand [5]. Direct Current (DC) fast charge with a typical 208/480V AC three-phase input [4] on the other hand can quickly overload the local distribution circuit. Additionally, PEV charging tends to increase transformer losses, voltage deviations, harmonic distortion, peak load and thermal loading on a distribution system [6]. Authors in [7] present impacts of fast charging represented by a 2-MW load, the equivalent of eight cars, and indicate that locations with a weak electrical infrastructure could not handle simultaneous fast PEV charging. Authors in [8] demonstrate that uncontrolled PEV charging leads to peak load in the 
early evening at residential sites, in the morning at the workplace and in the afternoon at commercial sites. An expensive way to manage such an impact is to reinforce the grid's infrastructure. However, instead of investing in the electricity infrastructure, impacts of PEV charging can be mitigated by exploiting the synergy among PEV charging, renewable generation and demand management (DM) [9].

With respect to the integration of solar photovoltaic (PV) into a PEV charging system, authors in [10] provide a review of PEV charging methods using PV-grid and standalone PV systems. Authors in [11] show a PV system with battery storage powering a residential PEV to reduce $\mathrm{CO}_{2}$ emissions. Authors in [5] indicate that solar-assisted PEV charging could reduce the peak load, but it is not a cost effective solution. Authors in [12] indicate that installation of PV panels to supply daytime charging of PEVs could not meet PEV's driving needs in winter. Authors in [13] study a public charging infrastructure integrated with PV and their results show that in urban environment, the high variability of renewable generation causes charging waiting delays. There are studies which discuss DM of PEV charging either by controlling or delaying PEV charging to reduce peak demand. Authors in [14] present different PEV charging scenarios including uncontrolled charging, delayed charging and off-peak charging to reduce grid impacts. Authors in [15] demonstrate DM of residential PEV charging, i.e., deferred charging, based on utility signals.

In addition to control of PEV charging, control of end-use loads in a building can effectively reduce peak load due to PEV integration. This study focuses on retail buildings, which include enclosed/strip malls and standalone outlets. Typically, lighting in U.S. retail (non-mall) buildings accounts for $26 \%$ and Heating Ventilation and Air-Conditioning (HVAC) $34 \%$ of total electricity consumption for non-mall buildings [16]. There are some studies which have demonstrated load control in retail buildings. Authors in [17] introduce daylighting, energy efficient lighting and HVAC system and a rooftop PV to a simulated hardware store and a visitor center to achieve electrical demand savings. Authors in [18] recommend the control of plug and process loads to reduce energy consumption. Authors in [19] show energy savings for two big box retail buildings. First store's cooling set point was raised by $2.9^{\circ} \mathrm{C}$ and second store's cooling set point was raised by $1.83^{\circ} \mathrm{C}$ to achieve annual cooling energy savings of $48 \%$ and $22 \%$ respectively. Authors in [20] show the reduction in annual electricity consumption in the range of $0.96 \%$ to $1.84 \%$ for $1{ }^{\circ} \mathrm{C}$ indoor air temperature set point modification for retail stores located in seven U.S. climate zones. A $20 \%$ reduction in lighting power densities in the seven stores resulted in annual electricity savings in the range of $8.86 \%$ to 10.09\%. Authors in [21] have implemented temperature setback and main sales lighting control strategies in big box retail buildings during a demand response event - defined as a period during which an utility requests customers to reduce their peak demand. Temperature set point was raised by $1{ }^{\circ} \mathrm{C}$ and main sales lights were shut down by $50 \%$, achieving $6 \%$ and $10 \%$ load reduction respectively. 
Literature review indicates that most studies have analyzed either PEV charge stations integrated with PV systems, DM of PEV charging, especially for PEV fleets in residential areas, or control of end-use loads for retail buildings to achieve demand savings. However, there are no studies which analyze the synergy between PV and DM of buildings' end-use loads to mitigate the impacts of PEV charging demand in retail buildings. This paper addresses this knowledge gap by analyzing the impacts of fast PEV charging on the retail building's load profile and quantify the benefit of PV and DM of building's end-use loads mainly HVAC and lighting - in absorbing PEV penetration. The DM algorithm designed for the retail building can lower the building's demand without sacrificing its functionality, while satisfying customer comfort. Realistic driving and charging behaviors of different types (e.g., Nissan Leaf, Chevrolet Volt) and classes (e.g., Sedan, SUV) of PEVs are considered in this study. Real-world PEV data are derived from PEV DC fast charging stations located at a retail site's on-street parking area. Approximately 12 months of PEV charge data have been collected and analyzed to determine PEV charge patterns and associated power consumption. Different types of PEVs with random batteries' State of Charge (SOC) indicate random driving patterns arriving at different times of the day at the public charging site. As PEVs are being integrated to the electric grid, it is essential to understand their charging behavior so that the grid can be managed to accommodate higher PEV penetration.

\section{Standalone retail building model in EnergyPlus}

This section summarizes the simulated retail building model and its end-use loads. EnergyPlus version 8.3, a building energy simulation tool, is used for this simulation study. The simulated standalone retail building model is based on the prototype medium-sized retail building model available in $[22,23]$ developed by National Renewable Energy Laboratory (NREL). According to the 2012 Commercial Buildings Energy Consumption Survey (CBECS) data, 96\% of retail buildings (non-mall) have an area up to $4,600 \mathrm{~m}^{2}$ [24]. The retail building model represents a medium box store with average level of retail activity, such as a clothing store, has little plug loads and is located in Virginia, U.S. area. Weather data used are of Ronald Reagan Washington National airport, U.S. available from [25].

\subsection{Building construction}

The simulated standalone retail building for this study is a $3762.57 \mathrm{~m}^{2}$ single-story building. The building is rectangular shaped with an aspect ratio of 1.25. Building envelope constructions include steel framed walls, flat roof with insulation above the deck and slab-on-grade floors. Windows are located on the south façade with a window-to-wall ratio of $22 \%$. The different zones include sales area, vestibule, stockroom, office, meeting room, break room, restroom, corridor and mechanical room.

\subsection{Building operation}

A weekday is considered for simulation purposes -- since on these days other commercial buildings such as office buildings are also operational and grid load is high. The occupancy, lighting, and electric equipment schedules as a fraction of peak densities on a typical weekday used in this study are shown in Figure 1. As shown, the building follows typical occupancy 
patterns for a retail building with peak occupancy between $11 \mathrm{am}$ to $1 \mathrm{pm}$ and $5 \mathrm{pm}$ to $7 \mathrm{pm}$ on weekdays. Lighting (general and accent) and equipment usage is high from 9am to 9pm. HVAC system operates all day. This information is necessary to analyze a building load profile when DM is performed to ensure customer comfort.

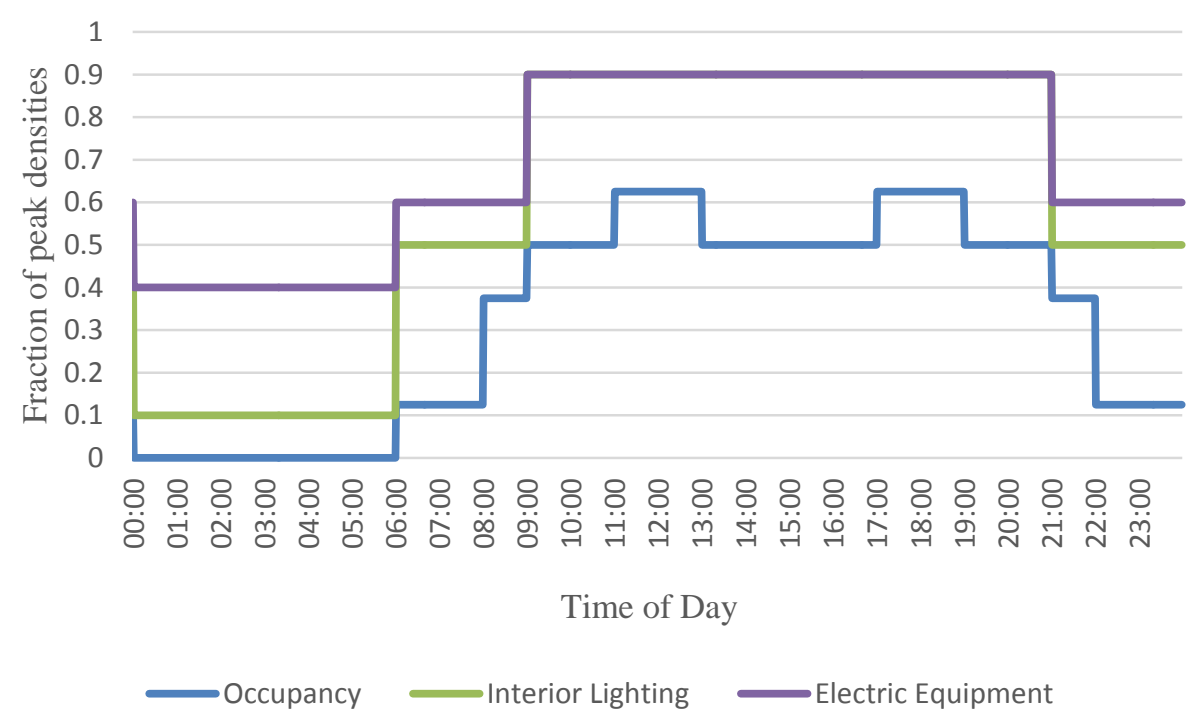

Fig. 1 Typical weekday schedules for occupancy, lighting and equipment of the standalone retail building

\subsection{HVAC load}

Each zone has a single packaged rooftop unit with constant air volume (CAV) distribution. Each packaged unit has a direct exchange (DX) cooling coil and a gas fired furnace. In addition, each zone has an electric baseboard heat to maintain comfort. For a summer weekday from 6 am to $12 \mathrm{am}$ the normal operating cooling set point is $24^{\circ} \mathrm{C}$. From midnight to 6 am the cooling temperature set point is $30^{\circ} \mathrm{C}$.

\subsection{Occupants, lighting and equipment}

Retail lighting can be general or accent [26]. General lighting provides uniform illuminance, while accent lighting provides additional illuminance to draw attention and emphasize specific items of merchandize [27]. Table 1 shows the occupant, lighting and plug load densities for different space types. The occupant density is measured in area $\left(\mathrm{m}^{2}\right)$ per person. Lighting power density is measured in terms of power consumption of lighting load (Watt) per unit area $\left(\mathrm{m}^{2}\right)$. Similarly, plug load density is measured in terms of power consumption of plug loads (such as cash registers, computers, monitors, printers, and copiers) per unit area $\left(\mathrm{m}^{2}\right)$. This study considers fluorescent lamps, most commonly used for general illumination in retail establishments [28], for providing general lighting for the simulated retail building. As light-emitting diodes (LEDs) are increasingly being used to provide retail accent lighting [28], LED lamps are considered to provide accent lighting on the simulated retail building's sales floor.

Table 1 Standalone retail building occupant, lighting and plug load densities 


\begin{tabular}{|c|c|c|c|c|}
\hline Zone type & $\begin{array}{c}\text { Zone Area } \\
\left(\mathrm{m}^{2}\right)\end{array}$ & $\begin{array}{c}\text { Peak occupant } \\
\text { density } \\
\left(\mathrm{m}^{2} / \text { person }\right)\end{array}$ & Lighting power density $\left(\mathrm{W} / \mathrm{m}^{2}\right)$ & Plug load density $\left(\mathrm{W} / \mathrm{m}^{2}\right)$ \\
\hline Sales floor & $2,982.19$ & 15.48 & $\begin{array}{c}12.38 \text { (general lighting) } \\
8.07 \text { (accent lighting) }\end{array}$ & 4.31 \\
\hline Vestibule & 27.87 & 15.48 & 4.84 & 0.00 \\
\hline Corridor & 55.74 & 0.00 & 5.81 & 0.00 \\
\hline Restroom & 69.68 & 15.48 & 9.26 & 8.08 \\
\hline Stock room & 418.06 & 27.93 & 9.26 & 8.07 \\
\hline Office & 41.81 & 18.59 & 8.72 & 8.07 \\
\hline Meeting room & 69.68 & 1.86 & 8.72 & 27.99 \\
\hline Break room & 69.68 & 1.33 & 4.84 & 0.00 \\
\hline Mechanical room & 27.87 & 0.00 & 9.26 & \\
\hline
\end{tabular}

The parking area of the simulated retail building is $9,406 \mathrm{~m}^{2}$, which is about 2.5 times larger than the building. The exterior lights in the parking area consume $15,188 \mathrm{~W}$ and turn on and off with sunset and sunrise respectively. The simulated retail building has a $0.1893 \mathrm{~m}^{3}$ electric water heater storage tank to provide hot water to the sinks and lavatories. The water heater continuously cycles on and off to maintain a temperature set point of $60^{\circ} \mathrm{C}$ within the specified dead band of $2^{\circ} \mathrm{C}$. Upon reaching the temperature set point the heater turns off.

\section{PEVs profiles for the simulated retail building}

PEVs include both battery electric vehicles (BEVs) and plug-in hybrid electric vehicles (PHEVs). BEVs solely operate on electricity stored in a battery; like Nissan LEAF, BMWi3, Ford Focus Electric and Volkswagen-e-Golf. In contrast PHEVs have an internal combustion engine that can supplement the electric power train; like Ford C-MAX Energi, Chevy Volt and Toyota Prius Plug-in. BEVs have driving range of 129 to $161 \mathrm{~km}$, while a few luxury models have ranges up to $402 \mathrm{~km}$. PHEVs run on electricity for shorter ranges around 10 to $64 \mathrm{~km}$, upon depletion of battery the operation is switched over to an internal combustion engine running on gasoline [29].

PEV charging can be performed using Alternating Current (AC) level 1, AC level 2 and DC fast charging [30]. AC level 1 charging is suitable for homes. Charging is provided through a $120 \mathrm{~V} \mathrm{AC} \mathrm{plug} \mathrm{and} 3.2$ to $8 \mathrm{~km}$ of range can be delivered per hour of charging. AC level 2 charging, suitable for workplace and public charging, is done through a $240 \mathrm{~V}$ (for residential) or $208 \mathrm{~V}$ (for commercial) plug. About 16 to $97 \mathrm{~km}$ of range can be delivered per hour of charging. DC fast charging, suitable for public charging stations, is provided through a 480V AC input and can deliver 97 to $161 \mathrm{~km}$ of range in about 20 minutes [31]. Table 2 below summarizes electric range and power consumption of different PEVs [32-36].

Table 2 Electric range and power consumption of different PEVs

\begin{tabular}{|l|l|l|l|l|l|l|l|l|}
\hline & & & \multicolumn{2}{|l|}{ AC Level 1 } & \multicolumn{2}{l|}{ AC Level 2 } & \multicolumn{2}{l|}{ DC fast charging } \\
\hline & Battery & All & Power & Charging & Power & Charging & Power & Charging \\
& capacity & electric & consumption & duration & consumption & duration & consumption & duration \\
\hline
\end{tabular}




\begin{tabular}{|c|c|c|c|c|c|c|c|c|}
\hline & $(\mathrm{kWh})$ & $\begin{array}{l}\text { range } \\
(\mathrm{km})\end{array}$ & $(\mathrm{kW})$ & (hours) & $(\mathrm{kW})$ & (hours) & $(\mathrm{kW})$ & (minutes) \\
\hline $\begin{array}{l}\text { Toyota } \\
\text { Prius Prime }\end{array}$ & 8.8 & 40.2 & 1.4 & 5.5 & 3.3 & 2.17 & - & - \\
\hline $\begin{array}{l}\text { Chevrolet } \\
\text { Volt PHEV } \\
2017\end{array}$ & 18.4 & 85.3 & 1.4 & 13 & 3.84 & 4.5 & - & - \\
\hline $\begin{array}{l}\text { Mitsubishi } \\
\text { i-MiEV } \\
2017\end{array}$ & 16 & 100 & 1.4 & 14 & 7.2 & 6 & 50 & 30 \\
\hline Nissan Leaf & 24 & 135 & 1.8 & $18-20$ & $\begin{array}{l}3.3 \\
6.6\end{array}$ & $\begin{array}{l}6-8 \\
4-5\end{array}$ & $48-50$ & $20-30$ \\
\hline 2016 & 30 & 172 & $0.8-1.2$ & 26 & $\begin{array}{l}3.3 \\
6.6\end{array}$ & $\begin{array}{l}5.5 \\
9.5\end{array}$ & $48-50$ & $20-30$ \\
\hline $\begin{array}{l}\text { Tesla Model } \\
\text { S }\end{array}$ & 100 & 506.9 & 1.1 & 90 & 12 & $9-10$ & 120 & $30-40$ \\
\hline
\end{tabular}

Fast charging is done through different connectors including CHAdeMO, an abbreviation for "CHArge de MOve" equivalent to "charge for moving", Society of Automotive Engineers (SAE) Combo Charging System (CCS) and Tesla Supercharger [37]. Nissan Leaf and Mitsubishi i-MiEV use CHAdeMO [38], which only supports DC fast charging. Chevrolet Volt, BMW i3, Chevrolet Spark and Volkswagen e-Golf use SAE CCS [38], which supports both slow and fast charging. Tesla Supercharger can only be used with Tesla vehicles and through vehicle adaptors can use CHAdeMO connectors.

PEV charging power consumptions, at charge stations located at a retail site's on-street parking, have been monitored and data recorded over 30 minute segments for a year was made available (courtesy of Dominion Virginia Power). The site has a 50kW DC fast charging station and a 50kW SAE CCS station which has both DC fast charging and a SAE J1772 AC level 2 charger. The PEV DC fast charging stations are added to the simulated retail building's existing electric service. That is, the aggregated PEV power consumption at the monitored stations is added to the simulated retail building's existing power consumption. Upon plugging-in to an available charge station, PEV owners are allowed to charge their cars instantly without any delayed charging.

Figure 2 illustrates two aggregated PEV charge profiles used in this study. From the annual daily charge profile data available, the selected profiles represent typical and diverse PEV charge behaviors that combine charging profiles of various PEV models 
with random levels of batteries' SOC indicating diverse driving patterns. In general, BEV drivers have more range anxiety than PHEV drivers hence it is assumed that usage of PEV charge station at the retail site would be more by BEV drivers. However, a survey [39] shows that higher range PHEV drivers (e.g., Chevrolet Volt) and BEV drivers (e.g., Nissan Leaf) charge more often than smaller range PHEVs drivers (e.g., Toyota Prius) and that usage of charging station is dependent upon the PEV owner behavior. From PEV charge profiles, shown in Figure 2, it is observed that mostly PEVs are publicly charged in the late morning, afternoon and evening times. As there are only two 50kW chargers hence only two PEVs with low SOCs can be fast charged simultaneously consuming a maximum of 100kW. The PEV charge profile "a" shows around 80kW being consumed from 5pm to 5:30pm due to two PEVs being fast charged simultaneously. The PEV charge profile "b" has a peak of around $93 \mathrm{~kW}$ from $12: 30 \mathrm{pm}$ to $1 \mathrm{pm}$.

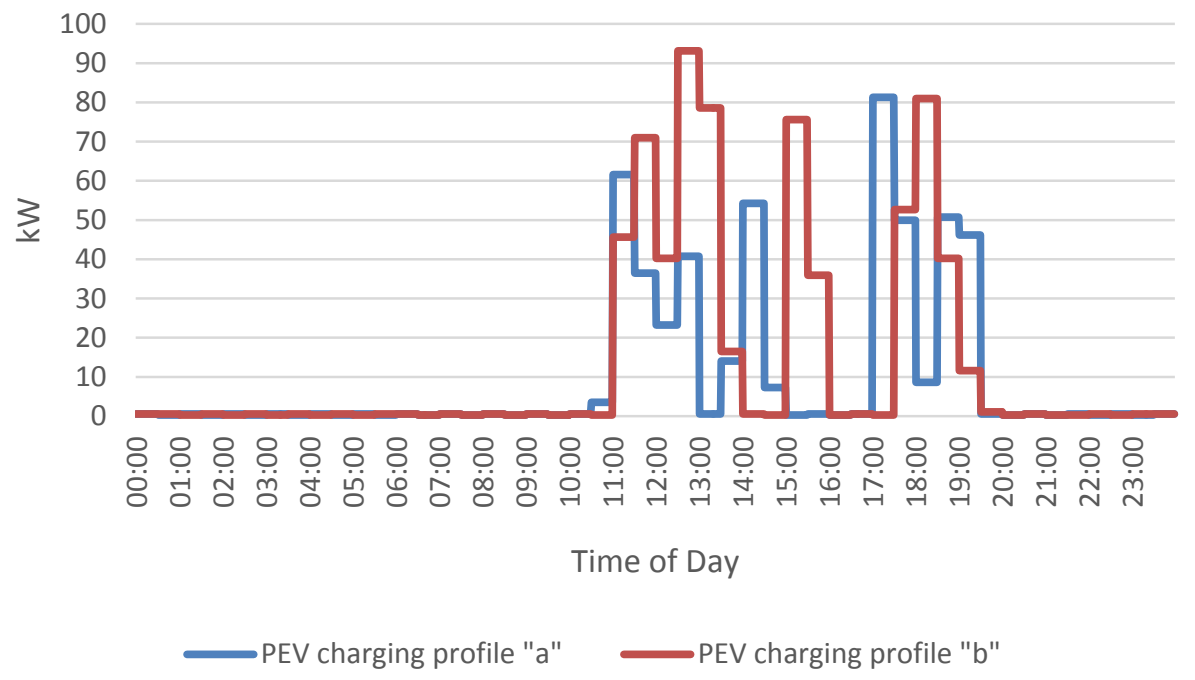

Fig. 2 PEV charging profiles considered in this study

\section{Modeling PV in EnergyPlus}

A standalone PV system has been modeled in EnergyPlus. After meeting PEV charge load, any excess PV generation is fed to the simulated retail building. Equivalent-one diode PV model available in EnergyPlus has been used for modeling LG PV module, LG230M1C. As the site has two 50kW DC fast charging stations, hence the maximum additional PEV charge power consumption can be $100 \mathrm{~kW}$ when two PEVs are being charged simultaneously. Therefore in this study one of the criteria for determining the size of PV is that the minimum PV peak capacity should be 100kW. As each modeled LG PV module has a peak capacity of $230 \mathrm{~W}$, a total of 540 modules results in a peak PV capacity of about $124 \mathrm{~kW}$. Instead of keeping PV peak capacity at $100 \mathrm{~kW}$, an excess of $24 \mathrm{~kW}$ is allowed, as in real conditions PV output is usually lower than the rated power at standard conditions. The modeled building roof has an area of $3762.57 \mathrm{~m}^{2}$. A total of 540 modules, 36 parallel strings of 15 modules in 
series, are installed with an inter-row spacing of $0.6 \mathrm{~m}$ and a tilt angle of $15.14^{\circ}$ as discussed in [40] to cover $1376.53 \mathrm{~m}^{2}$, about $37 \%$ of the building's roof area. An inverter with rated maximum continuous output power of $110 \mathrm{~kW}$ (power rating of PV is considered higher than the AC output rating of the inverter as discussed in [40]), Satcon PV-110-S-480Vac, available in [41] is selected. The inverter's nominal input voltage is $320 \mathrm{~V}$ with a standby power loss of $74.30 \mathrm{~W}$. Inverter efficiencies are generally higher than $95 \%$. Battery storage has not been considered in this research due to additional cost and energy requirements for recharging.

\section{Proposed methodology}

This section summarizes the methodology developed to absorb PEV penetration at the retail site using a renewable energy source, i.e., PV, and DM of end-use loads. The objective of the proposed methodology is to keep PEV penetration transparent, i.e., absorb additional increase in building peak demand. Simulations are performed at 1-minute intervals.

\subsection{PV operation}

PEV owners, arriving at the available charging stations, are given priority over building requirements to charge their vehicles instantly without any delay. PEV charge profiles, as shown in Figure 2, increase the simulated retail building's demand. The PV generation, available all day but dependent upon weather conditions, attempts to absorb this increased demand due to PEV charging. At each time step, i.e., at 1- minute intervals, PV output varies as per changes in solar irradiance on the simulated day. During the absence of PEV charging any surplus PV energy is fed to the simulated retail building to meet its electrical demand.

\subsection{DM of end-use loads}

If PV alone is unable to absorb the increased in building load due to PEV charging, then DM of lighting and HVAC -- two major energy consuming loads -- is performed to further reduce the building's electrical demand. During low or no PV generation, i.e., during evening and night time, DM alone has to absorb PEV generation.

Zones' priorities for DM - All zones in the retail building have been allocated a priority based on which their lighting and HVAC loads are controlled. Lower priority zones' lights and HVAC are controlled first in an attempt to absorb PEV penetration followed by higher priority zones. Table 3 shows the allocated zones' priorities for the application of DM. Priorities have been assigned in order of increasing occupant density and also significance of performed activity. All zones other than the vestibule and sales areas have been assigned lower priority as these zones do not have the sales potential. That is, these areas are not for display or appraisal of merchandise, and do not need to be appealing as there is no customer influx. Zones like mechanical room, corridor have been assigned the lowest priority, "6", due to lowest occupancy. Breakroom and meeting room, with next higher occupant density, have been assigned a priority of " 5 ". Office and restroom have been assigned a priority of " 4 " due to high occupant density. Office lighting is as important as any corporate office lighting. Stockroom has been assigned a priority of "3" due to its high occupant density and this zone involves the task of reading of labels and identifying merchandise [42]. Vestibule 
has been assigned a priority " 2 " as a shopper's first impression is shaped at the store's entrance. The lighting here should be pleasing and facilitate safe passage and create sense of security [42]. Sales areas' lights and HVAC are controlled last to absorb PEV penetration as these zones need to be comfortable and should appear attractive to the customers in order to encourage shopping. Perimeter sales areas allow daylight control as these zones receive natural daylight hence they are controlled first before the main sales area and assigned lower priority than the main sales area. Sequence of HVAC and lighting control for each zone is discussed below.

Table.3 Designated zone priorities for DM of lighting and HVAC

\begin{tabular}{|l|l|l|}
\hline Zone & $\begin{array}{l}\text { Order of } \\
\text { increasing } \\
\text { priority }\end{array}$ & Reason for priority assignment \\
\hline Mechanical room/Corridor & 6 & Lowest occupant density \\
\hline Breakroom/Meeting room & 5 & Next highest occupant density \\
\hline Office/Restroom & 4 & $\begin{array}{l}\text { Store offices should reflect the store's image. Lighting } \\
\text { as important as in a corporate office. Next highest } \\
\text { occupant density }\end{array}$ \\
\hline Stock room & 3 & $\begin{array}{l}\text { Reading labels and identifying merchandise are the } \\
\text { primary objectives. High occupant density }\end{array}$ \\
\hline Vestibule/Perimeter sales area & 2 & $\begin{array}{l}\text { These zones need to be appealing. Daylight control } \\
\text { possible as these zones receive daylight }\end{array}$ \\
\hline Main sales area & $\begin{array}{l}\text { Zone needs to be comfortable and attractive, customers } \\
\text { should be able to easily evaluate product and hence this } \\
\text { zone is controlled the last }\end{array}$ \\
\hline
\end{tabular}

Algorithm for DM - Control algorithm to dynamically control each zone's lights and HVAC has been developed using EnergyPlus Energy Management System (EMS). Whenever DM is required, lights and HVAC are controlled at each time step, i.e., at 1-minute intervals, without sacrificing customers or employees comfort requirements. Summer cooling set points in each zone are raised that do not compromise thermal comfort. Fanger's Predicted Mean Vote (PMV) index is used to measure occupants' thermal comfort - with comfortable range between -0.5 and +0.5 - which takes into account air temperature, mean radiant temperature, relative humidity, air speed and two personal factors including activity and clothing [43]. With raised cooling set points, PMV in each zone is kept lower than +0.5 to maintain thermal comfort [43]. Ambient lighting levels are varied to maintain an average ambient illumination level of 500 lux [42, 44, 45], as recommended by Illuminating Engineering Society of North America (IESNA), in the simulated retail building. For zones which receive daylight, all general lights are shutdown if daylight light levels exceed 500 lux. Dimming lights has an added benefit of reducing cooling load. The order in which DM of lighting and HVAC load is performed is explained in Table 4. After each zone's lighting levels and cooling set points are adjusted, it is checked whether PEV penetration has been completely absorbed or not. If not, then the next higher priority zone is controlled. For all zones first their HVAC load is controlled and then lights. Lighting for zones with high priorities "1" and "2", which are sales area, are controlled last as lighting plays an important role in these zones. For sales area 
(main sales and perimeter sales), only general lights are controlled not the accent lighting so that product visibility is not greatly affected.

Table.4 DM of lighting and HVAC based on zones' priorities

\begin{tabular}{|c|c|}
\hline Order of Control & Control Algorithm for DM \\
\hline Step 1 & $\begin{array}{l}\text { Adjust cooling set points first to maintain PMV }<+0.5 \text { and next adjust lights to } \\
\text { maintain 500lux for zones with lowest priority " } 6 \text { " }\end{array}$ \\
\hline Step 2 & $\begin{array}{l}\text { Adjust cooling set points first to maintain PMV }<+0.5 \text { and next adjust lights to } \\
\text { maintain 500lux for zones with priority " } 5 \text { " }\end{array}$ \\
\hline Step 3 & $\begin{array}{l}\text { Adjust cooling set points first to maintain PMV }<+0.5 \text { and next adjust lights to } \\
\text { maintain 500lux for zones with priority " } 4 \text { " }\end{array}$ \\
\hline Step 4 & $\begin{array}{l}\text { Adjust cooling set points first to maintain PMV }<+0.5 \text { and next adjust lights to } \\
\text { maintain 500lux for zones with priority " } 3 \text { " }\end{array}$ \\
\hline Step 5 & $\begin{array}{l}\text { Adjust cooling set points to maintain PMV }<+0.5 \text { for zones with priorities " } 2 \text { " } \\
\text { and " } 1 \text { " }\end{array}$ \\
\hline Step 6 & $\begin{array}{l}\text { Lighting for zones with priority " } 2 \text { " is controlled. If daylight } \\
\text { illuminance>500lux than shutdown all general lights. If daylight } \\
\text { illuminance<500lux than adjust lights so that general light and daylight } \\
\text { together produce 500lux }\end{array}$ \\
\hline Step 7 & Adjust lights for zone with priority "1" to maintain 500lux \\
\hline
\end{tabular}

\section{Simulation Results and Discussions}

This Section presents simulation results for the simulated retail building for a typical summer day in Virginia, reflecting average weather conditions that prevail most of the summer time. All simulations are performed at a resolution of 1- minute intervals.

\subsection{Building power consumption}

Figure 3 shows the load profile for the simulated retail building on the simulated day, as well as power consumption profiles by load type. The outside air dry bulb temperature is higher than $30^{\circ} \mathrm{C}$ from around 12 noon to $6 \mathrm{pm}$ for the simulated day as shown in Figure 3. HVAC operated in a cooling mode consumes higher power than lighting and electric equipment. The building's power consumption, which is the sum of individual loads like HVAC, lighting and electric equipment, has spikes due to the on and off cycling of the electric water heater. The water heater adds around 30kW to the building load when operational to maintain the hot water temperature. The overall building power consumption is high from $6 \mathrm{~mm}$ to $9 \mathrm{pm}$ due to high internal loads. Upon sunset at 7:30pm, the exterior lights turn on and there is an increase in building power consumption, resulting in a peak load of $218.48 \mathrm{~kW}$ at $7: 50 \mathrm{pm}$. At $9 \mathrm{pm}$ building occupancy level, lighting and plug load usage reduce to $37.5 \%, 50 \%$ and $60 \%$ respectively, thereby reducing the overall building power consumption from what it was during the afternoon. From midnight to 6am in the morning, building power consumption goes down further as occupancy levels, lighting and plug load usage reduce further to $0 \%, 10 \%$ and $40 \%$ respectively. 


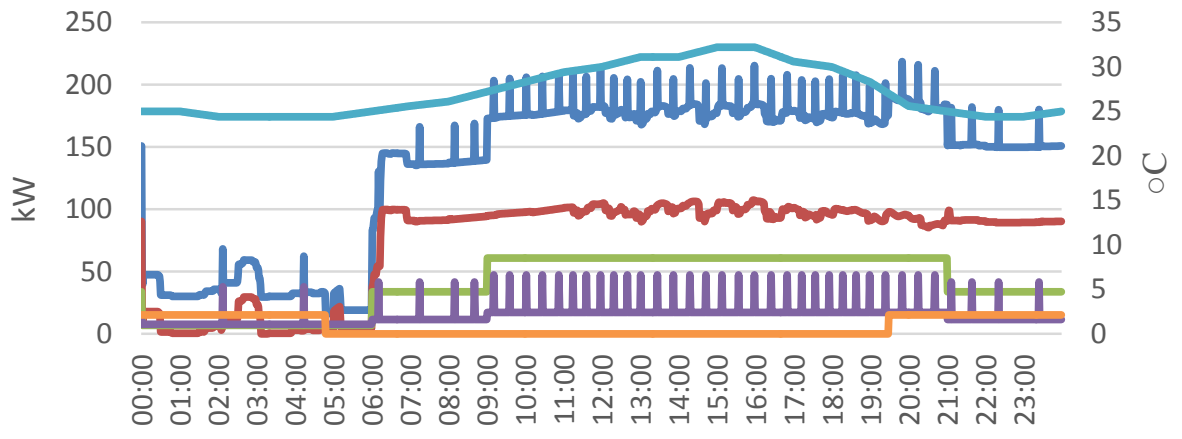

Time of Day

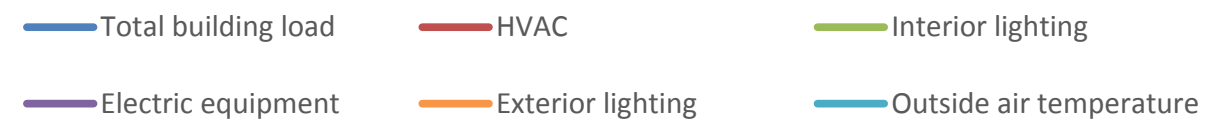

Fig. 3 Power consumption profiles of HVAC, lighting (interior/exterior) and electric equipment, as well as the total building load, which is the sum of individual loads for the retail building without PEV penetration for a summer day

Figures 5 and 6 show the simulated retail building's power consumption with PEV penetration, where PEV power consumption profiles, as shown in Figure 2, are integrated to the original simulated retail building's power consumption profile, shown in Figure 3. The random and unpredictable PEV charging causes the simulated retail building's load to randomly fluctuate.

Table 5 summarizes the occurrence of simulated retail building's peak demand with each PEV charge profile. PEVs' random charging introduces new building peak demands. PEVs following charging profile "a" cause peak demand in the evening hours when residential buildings have peak demand due to return of residents from work. The profile "b" produces peak demand in the afternoon hours when most commercial buildings, like office buildings, have peak demand due to high cooling loads.

Table.5 Simulated retail building's peak load due to PEV penetration

\begin{tabular}{|c|c|c|c|}
\hline PEV charge profiles & $\begin{array}{c}\text { Peak time of the } \\
\text { building load with } \\
\text { PEV }\end{array}$ & $\begin{array}{c}\text { Peak load with PEV } \\
\text { at the new peak time } \\
(\mathrm{kW})\end{array}$ & $\begin{array}{c}\text { \% Increase from the original } \\
\text { building peak load } \\
(218.48 \mathrm{~kW}) \text { at 7:50pm }\end{array}$ \\
\hline Profile a & $5: 13 \mathrm{pm}$ & 285.11 & 30.50 \\
\hline Profile $\mathrm{b}$ & $12: 40 \mathrm{pm}$ & 297.50 & 36.17 \\
\hline
\end{tabular}

\subsection{PV's ability to absorb PEV penetration}

Figure 4 shows the PV output for the simulated retail building and the simulated day without PEV penetration. The simulated day is a typical summer day with enough solar irradiance available. The sky clearness factor describes attenuation of solar radiation due to clouds and indicates an overcast sky when close to 1 and a clear sky when greater than 6 . For the simulated day the sky clearness factor reaches a maximum value of 3.26 at 11:30am. At this time PV output peaks to $97.42 \mathrm{~kW}$. This maximum PV output reduces building demand at $11: 30 \mathrm{am}$ from $176 \mathrm{~kW}$ to $74.83 \mathrm{~kW}$, a decrease of $57.48 \%$. However, building peak demand occurs at 7:50pm when PV is zero due to non-availability of solar irradiance. PV produces $2.34 \mathrm{GJ}$ of energy on the 
simulated day, thereby reducing the building's energy consumption from $11.57 \mathrm{GJ}$ to $9.06 \mathrm{GJ}$, a decrease of $21.69 \%$. It is also noted that HVAC peak demand and energy consumption are also reduced from $137.34 \mathrm{~kW}$ to $134.68 \mathrm{~kW}$ and $6.33 \mathrm{GJ}$ to $6.16 \mathrm{GJ}$ respectively due to shading of roof by PV panels which help reduce the building's cooling load.

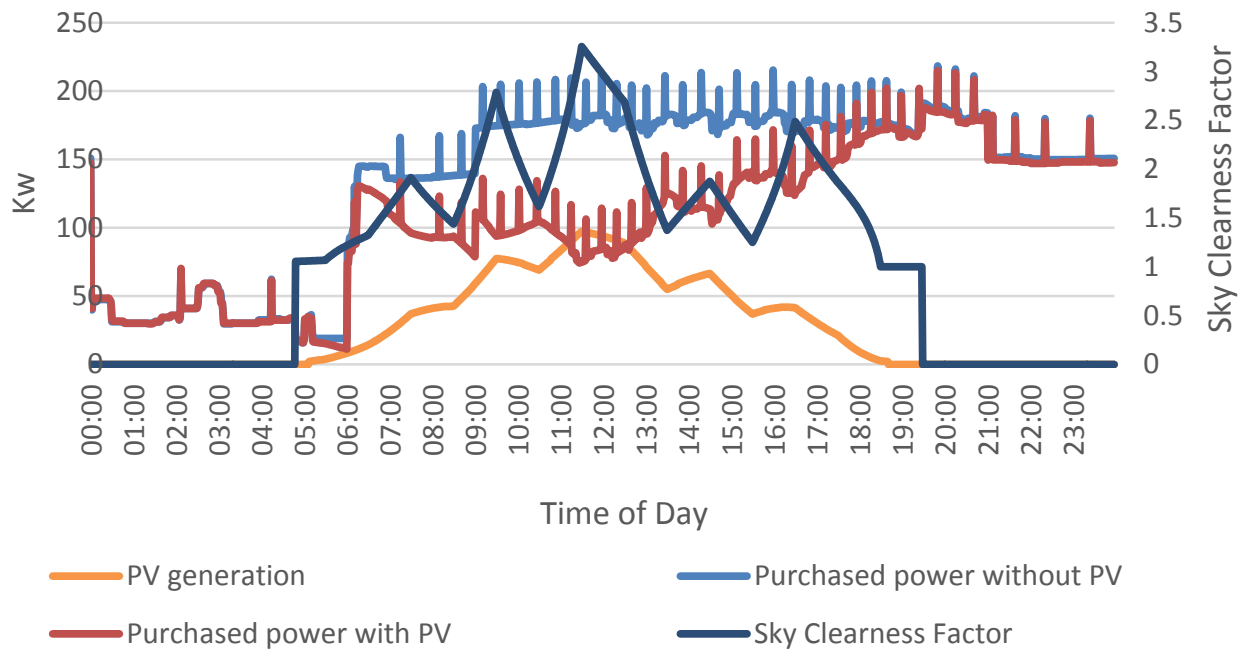

Fig. 4 Simulated retail building's power consumption profile for the simulated day with PV generation and without PEV penetration

Figure 5 shows the simulated retail building's power consumption with PV generation and PEV penetration. From Figure 5 it is observed that PV alone is not able to always keep the simulated retail building's demand with PEV charging lower than its original demand without PEV charging. This is due to the fact that PV generation is intermittent and highly dependent upon weather conditions. PV output is less after reaching its maximum value of $97 \mathrm{~kW}$ at 11:30am due to lower values of sky clearness factor for the rest of the day. As evening approaches and the daylight illuminance level reaches zero, around 7:30pm, PV output is further reduced due to non-availability of solar irradiance. 


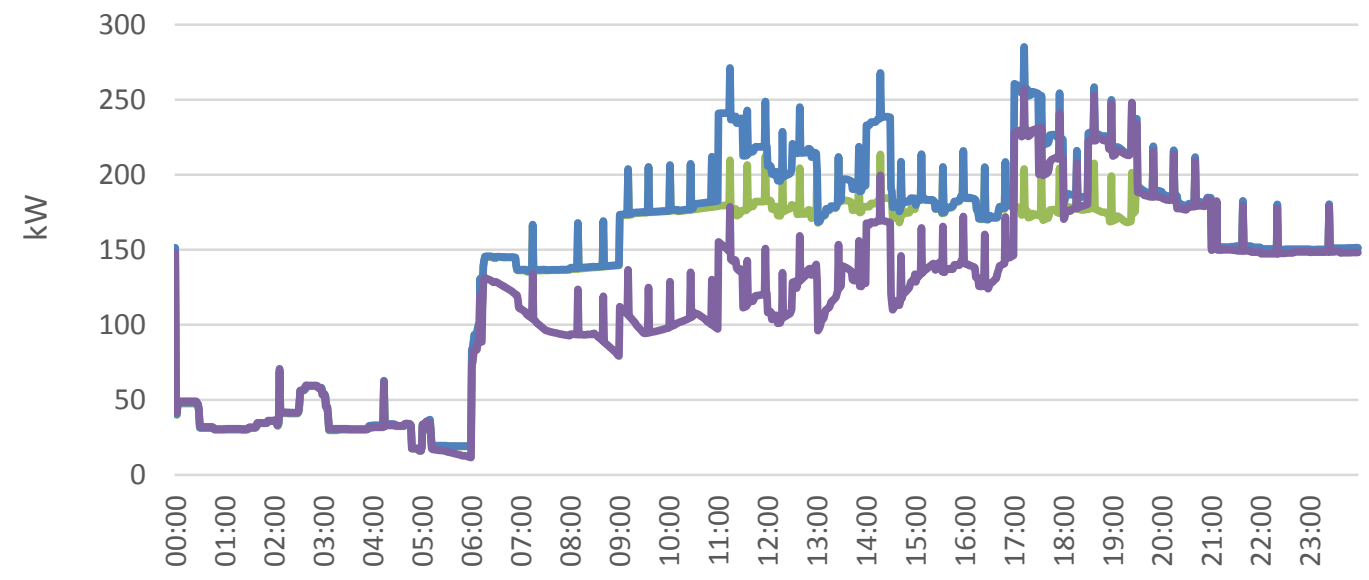

Time of Day

without PEV, PV w with PEV charging profile "a" — with PEV charging profile "a" and PV

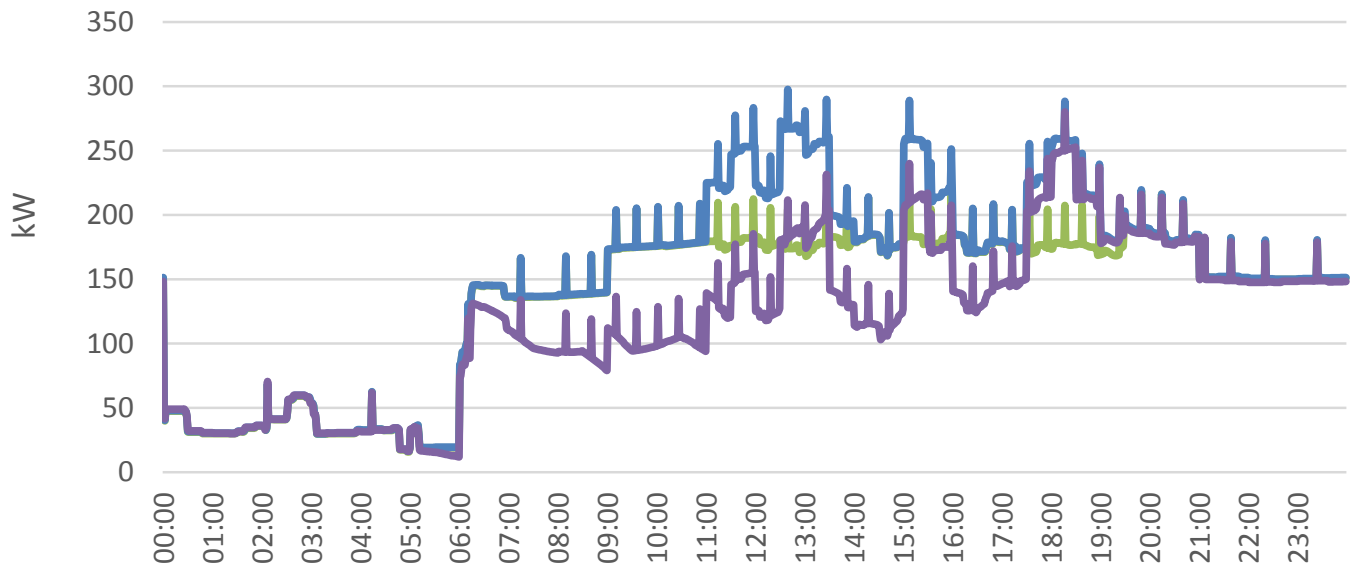

Time of Day

without PEV, PV with PEV charging, profile "b" with PEV charging, profile "b" and PV

Fig. 5 Simulated retail building's power consumption with PV for the simulated day with PEV penetration

It is also observed from Figure 5 that PV shifts building demand with PEV to later evening hours. The shifted building peak demand value with PEV and PV is lower than the original peak demand with PEV only. This is because in the afternoon hours building demand is high due to high cooling load, as shown in Figure 3, and PEV charging further exacerbates the situation. Presence of PV lowers this demand during day time due to enough solar irradiance. In the evening hours building cooling load is lower than afternoon hours, resulting in lower building demand, however reduced or absence of PV generation cannot absorb enough PEV penetration resulting in evening peaks.

\subsection{DM's ability to absorb PEV penetration}


Figure 6 shows the simulated retail building's power consumption with DM of end-use loads and PEV penetration. From Figure 6 it is observed that DM alone, like PV, is not able to keep the simulated retail building's demand with PEV charging lower than the original simulated retail building's demand without PEV charging. PEV charging can consume a maximum of 100kW, which DM of lights and HVAC is unable to absorb. This is because during daytime internal building loads are high along with outside air temperatures. From around $7 \mathrm{pm}$ daylight availability is limited hence daylight control effects are minimal on building's power consumption. From 9pm onwards 50\% lights are already shutdown due to lower occupancy hence there is not enough margin available to further shutdown lights and maintain required illuminance levels. For all zones the cooling set points were raised by a maximum of $3^{\circ} \mathrm{C}$, i.e. up to $27^{\circ} \mathrm{C}$. However, for the zones receiving daylight, the cooling set points could not always be maintained at $27^{\circ} \mathrm{C}$ during DM operation as these zones receive daylight and quickly get warmer causing the PMV index to go higher than +0.5 .

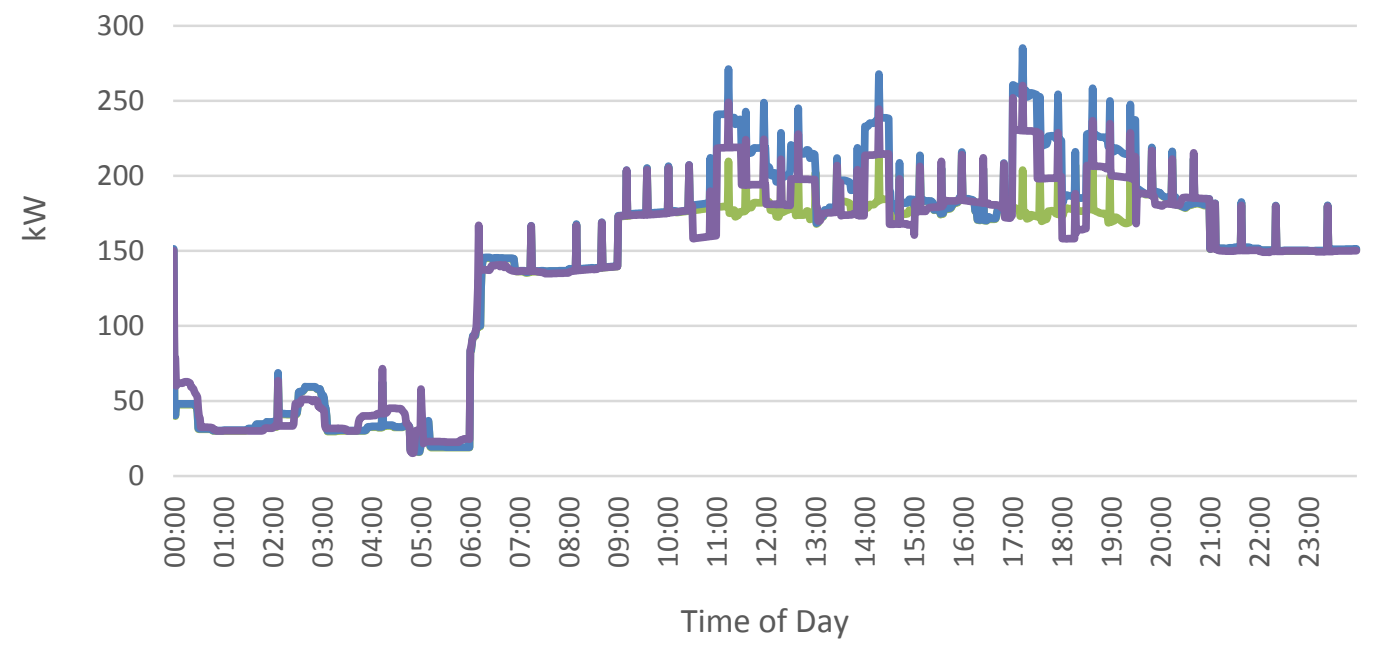

without PEV, DM with PEV charging, profile "a" with PEV charging, profile "a" and DM 


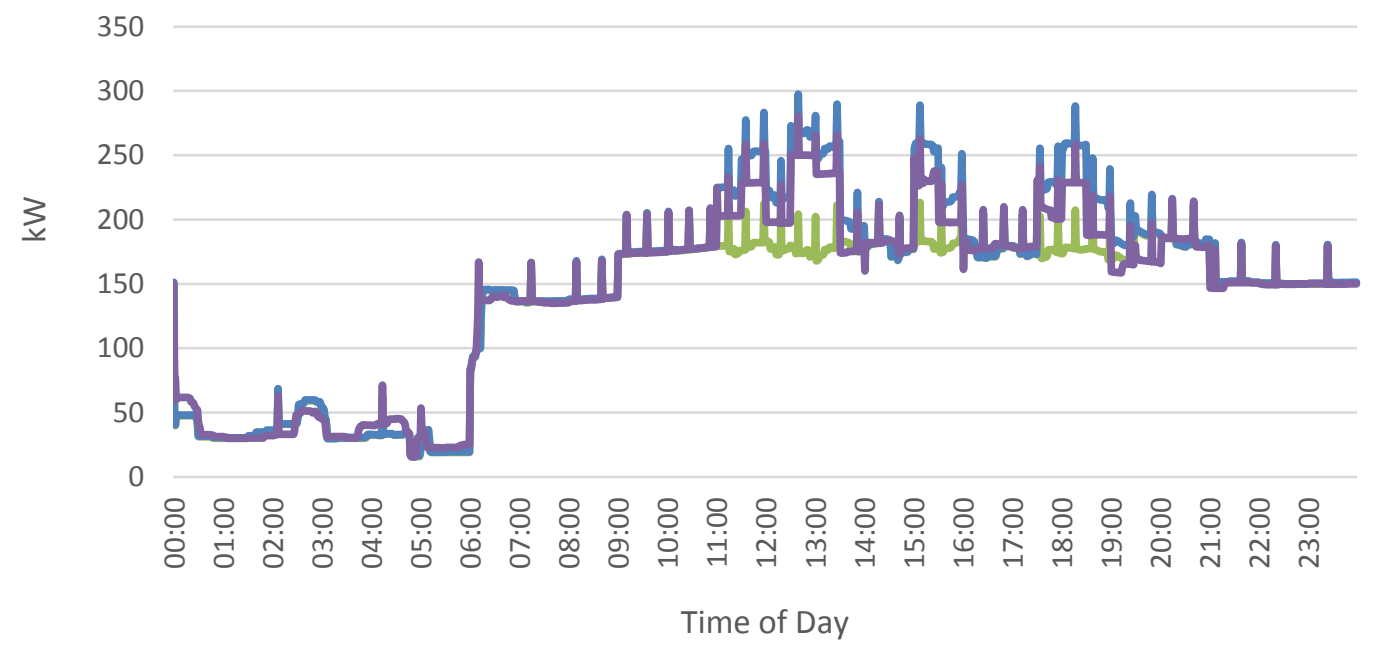

without PEV, DM with PEV charging, profile "b" with PEV charging, profile "b" and DM

Fig. 6 Simulated retail building's power consumption with DM for the simulated day with PEV penetration

It is observed that DM unlike PV does not shift building peak demand to evening hours. This is because unlike PV, DM is not available all day to lower building demand, it is operational only when PEV charging occurs. Also in the absence of solar irradiance, in the evening and night time hours, PV cannot absorb PEV penetration whereas DM can.

\subsection{DM plus PV's ability to absorb PEV penetration}

As observed in Sections 6.2 and 6.3, PV or DM individually is unable to fully absorb PEV penetration at the building level. Hence both are deployed together. First PV tries to absorb PEV penetration. If PV is unable to do so than DM of building enduse loads is applied along with PV to try to completely absorb PEV penetration.

Figure 7 shows the power consumption profiles for the simulated retail building with PEV fast charging, along with PV and DM to mitigate PEV charging impacts. It is observed that DM along with PV is able to keep the simulated retail building's demand lower than the original peak demand without PEV penetration during the afternoon peak hours. However, higher peak demand is observed during the evening hours. 


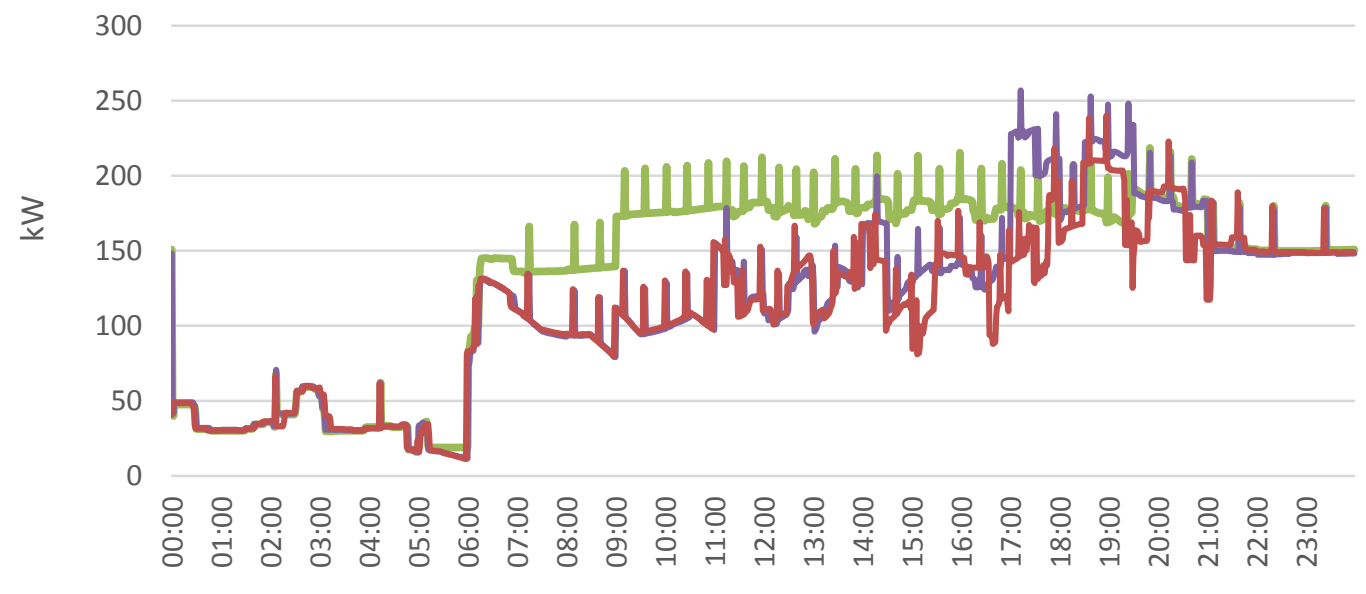

Time of Day

without PEV, PV, DM
with PEV charging, profile "a" and PV, DM

with PEV charging, profile "a" and PV

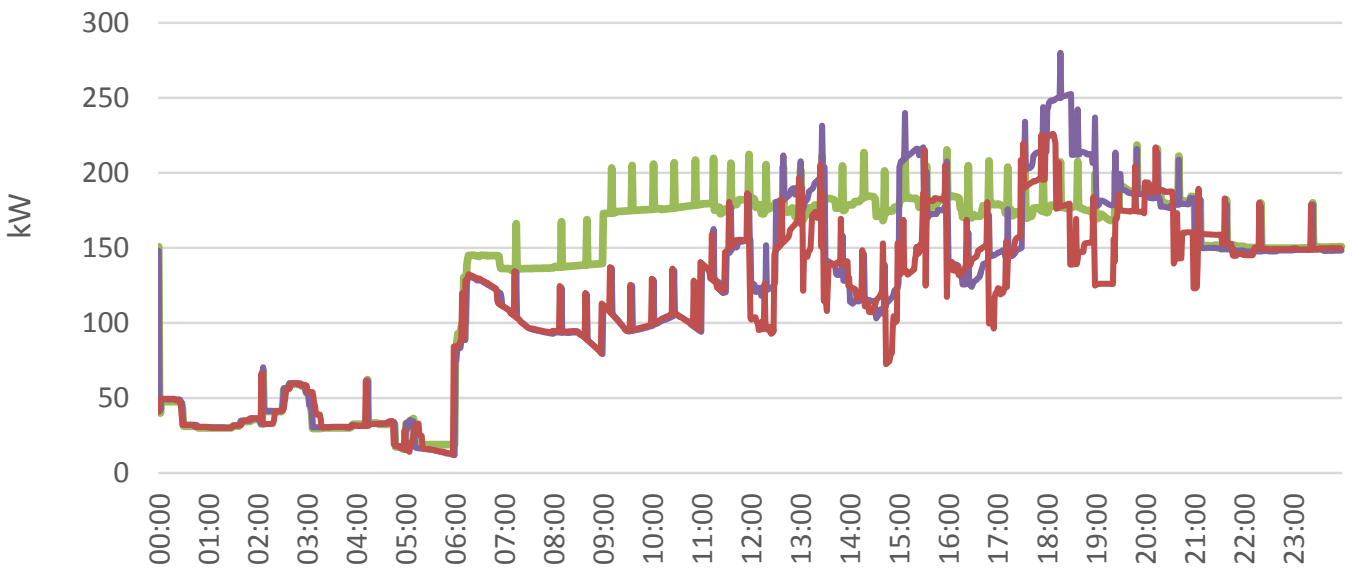

Time of Day

without PEV, PV, DM
with PEV charging, profile "b" and PV, DM

with PEV charging, profile "b" and PV

Fig. 7 Simulated retail building's power consumption with PV and DM for the simulated day with PEV penetration

Table 6 summarizes the increase in the simulated retail building's peak load due to PEV penetration and the ability of PV and

DM to absorb it. Case 0 is the scenario considering PEV penetration only in the simulated retail building. Case 1 illustrates the ability of PV to absorb PEV penetration. Case 2 illustrates the ability of DM to absorb PEV penetration, and Case 3 reveals the ability of both PV and DM to absorb PEV penetration.

It can be seen that Case 3 is able to fully absorb PEV penetration at the original building peak time, reducing simulated retail building's peak demand with PEV penetration than the original demand without PEV penetration for profile "a" by $13.74 \%$ and 
for profile "b" by $10.61 \%$. Overall, Case 3 enjoys the advantage of PV that is available during the day and that of DM that can lower building load during the day and early evening hours, thus producing better results than Cases 1 and 2 .

Table.6 Summary of simulated retail peak building's peak load due to PEV penetration, PV and DM

\begin{tabular}{|c|c|c|c|c|c|c|c|c|}
\hline \multirow[b]{2}{*}{$\begin{array}{c}\text { PEV } \\
\text { charge } \\
\text { profiles }\end{array}$} & \multirow{2}{*}{$\begin{array}{l}\text { Original } \\
\text { peak time } \\
\text { of the } \\
\text { building } \\
\text { load with } \\
\text { PEV }\end{array}$} & \multicolumn{5}{|c|}{ Building peak load at the original peak time } & \multirow{2}{*}{$\begin{array}{l}\text { New peak } \\
\text { time of the } \\
\text { building } \\
\text { load + } \\
\text { PEV+ PV+ } \\
\text { DM }\end{array}$} & \multirow{2}{*}{$\begin{array}{c}\text { Building } \\
\text { peak load } \\
+\mathrm{PEV} \\
+\mathrm{PV}+ \\
\mathrm{DM} \text { at } \\
\text { new peak } \\
\text { time } \\
(\mathrm{kW})\end{array}$} \\
\hline & & $\begin{array}{c}\text { without } \\
\text { PEV (kW) }\end{array}$ & $\begin{array}{c}\text { Case 0: } \\
\text { with PEV } \\
(\mathrm{kW})\end{array}$ & $\begin{array}{c}\text { Case 1: with } \\
\text { PEV + PV } \\
(\mathrm{kW})\end{array}$ & $\begin{array}{c}\text { Case 2: with } \\
\text { PEV and } \\
\text { DM } \\
(\mathrm{kW})\end{array}$ & $\begin{array}{c}\text { Case } 3: \\
\text { with PEV } \\
+\mathrm{PV}+\mathrm{DM} \\
(\mathrm{kW})\end{array}$ & & \\
\hline Profile b & $12: 40 \mathrm{pm}$ & 204.35 & 297.50 & 211.63 & 280.28 & 182.66 & 6:10pm & 226.02 \\
\hline
\end{tabular}

Table 7 shows the electrical energy consumption for the simulated retail building with PEV penetration, PV and DM, on the simulated day. PEV charge profile " $b$ " causes the simulated retail building to have a higher electrical energy consumption due to prolonged PEV charging. Case 1: PV only and Case 3: PV plus DM, with PEV penetration, reduce the simulated retail building's electrical energy consumption from the original consumption of 11.57GJ without PEV penetration which Case 2: DM only is not able to do so. This is because PV generation is available all day, when PEV is not being charged any excess generation available is fed to the building to meet its electrical demand.

Table.7 Summary of simulated retail building's electric energy consumption for the simulated day with PEV penetration, PV and DM

\begin{tabular}{|c|c|c|c|c|c|}
\hline \multirow{2}{*}{$\begin{array}{c}\text { PEV charge } \\
\text { profiles }\end{array}$} & Electrical energy consumption for the simulated day (GJ) \\
\cline { 2 - 6 } & without PEV & $\begin{array}{c}\text { Case 0: } \\
\text { with PEV only }\end{array}$ & $\begin{array}{c}\text { Case 1: } \\
\text { PEV + PV }\end{array}$ & $\begin{array}{c}\text { Case 2: } \\
\text { with PEV + DM }\end{array}$ & $\begin{array}{c}\text { Case 3: with } \\
\text { PEV + PV+ DM }\end{array}$ \\
\hline Profile a & 11.57 & 12.46 & 9.95 & 11.98 & 9.46 \\
\hline Profile b & 11.57 & 12.76 & 10.24 & 12.27 & 9.61 \\
\hline
\end{tabular}

Some key points are observed from the simulation results. Public PEV charging is high from late morning to evening hours. As public charging stations offer PEV owners the convenience of 24-hour accessibility, hence late night time PEV charging can take place and may not be controlled as grid load is lower and utilities want to spread the demand over whole day. Afternoon and evening PEV charging, when commercial buildings and residential customers cause high grid demand respectively need to be absorbed to reduce grid burden. A good sized PV maybe able to meet PEV power requirements when solar resource is high but not during evening hours as PV generation is weather dependent and decreases with lower solar resource. Storage along with PV can play a vital role to help completely absorb PEV penetration but it is a costly solution and needs extra energy for recharging. DM strategies along with PV generation can prove to be a viable option to absorb PEV penetration without additional energy usage. More stringent DM strategies -- such as further reduction in light levels (especially for less priority zones, e.g., meeting rooms, mechanical rooms, breakrooms, and restrooms) and selected HVAC control strategies (e.g., systemic adjustments to the 
air distribution and cooling systems) -- and a deployment of an appropriately sized PV can potentially absorb majority of added PEV load during the day.

\section{Conclusions}

Large scale integration of Plug-in Electric Vehicles (PEVs) to the electric grid presents potential technical challenges that need to be addressed. This paper studies the impacts of PEV Direct Current (DC) fast charging on a simulated retail building's peak demand and quantifies the benefit of solar photovoltaic (PV) and demand management in absorbing PEV penetration. An understanding of the public PEV charge pattern is crucial for the rollout of charging infrastructure. The study presents real world PEV charging characteristics taking into account different types and classes of PEVs and diverse driving patterns. Results indicate that fast PEV charging increases the building's peak load. This in turn leads to an increase in the associated peak demand charges. PV and demand management can help lower this building peak load and the associated peak utility charges hence, encouraging the building owners to install on-site PEV charge stations. This awareness leads to widespread adoption of public PEV charge stations to reduce range anxiety of potential PEV drivers. A very large sized PV may be able to absorb day time PEV penetration completely but still is weather dependent and especially during winters availability of solar energy is limited. Results indicate that an appropriately sized PV or demand management alone may not be able to completely absorb PEV penetration, while maintaining occupant comfort. However, stringent demand management strategies along with PV have the potential to absorb PEV fast charging at the building level thereby enabling the electric grid to accommodate PEV penetration, i.e., making the new PEV load transparent to the grid. In this study PV along with demand management can absorb PEV penetration at the building level up to an average of $38 \%$ and can shift building peak demand to late evening hours which is beneficial for utilities as during this time the grid faces less stress. Research findings can be of interest to power utilities, automobile companies and retail sites hosting PEV charge stations who would like to understand charge patterns and impacts of PEV penetration at the building level, as well as the contribution of PV and demand management that can help mitigate such impacts.

\section{Acknowledgement}

This material is based upon work supported by U.S. National Science Foundation under Grant\# ECCS-1232076. We thank

Dominion Virginia Power for providing PEV charge data.

\section{References}

1. Vehicle Technologies Office:Plug-in Electric Vehicles and Batteries. [cited 2016; Available from: http://energy.gov/eere/vehicles/vehicle-technologies-office-plug-electric-vehicles-and-batteries.

2. Overcoming Barriers to Electric-Vehicle Deployment: Interim Report 2013, National Academy of Sciences.

3. Yilmaz, M. and P.T. Krein, Review of Battery Charger Topologies, Charging Power Levels, and Infrastructure for Plug-In Electric and Hybrid Vehicles. IEEE Transactions on Power Electronics, 2013. 28(5).

4. Developing Infrastructure to Charge Plug-In Electric Vehicles. 2016; Available from: http://www.afdc.energy.gov/fuels/electricity_infrastructure.html.

5. Initiative on Plug-in Electric Vehicles. 2012, Illinois Commerce Commission. 
6. Yong, J.Y., et al., A review on the state-of-the-art technologies of electric vehicle, its impacts and prospects. Renewable and Sustainable Energy Reviews, 2015. 49: p. 365-385.

7. Etezadi-Amoli, M., K. Choma, and J. Stefani, Rapid-Charge Electric-Vehicle Stations. IEEE Transactions on Power Delivery, 2010. 25(3): p. 1883-1887.

8. Weiller, C., Plug-in hybrid electric vehicle impacts on hourly electricity demand in the United States. Energy Policy, 2011. 39(6): p. 3766-3778.

9. Weiller, C. and A. Neely, Using electric vehicles for energy services: Industry perspectives. Energy, 2014. 77: p. 194200.

10. Bhatti, A.R., et al., Electric vehicles charging using photovoltaic: Status and technological review. Renewable and Sustainable Energy Reviews, 2016. 54: p. 34-47.

11. Karan, E., S. Asadi, and L. Ntaimo, A stochastic optimization approach to reduce greenhouse gas emissions from buildings and transportation. Energy, 2016. 106: p. 367-377.

12. Birnie, D.P., Solar-to-vehicle (S2V) systems for powering commuters of the future. Journal of Power Sources, 2009. 186(2): p. 539-542.

13. Gharbaoui, M., et al. Effective management of a public charging infrastructure through a smart management system for electric vehicles. in Energy Conference and Exhibition (ENERGYCON), 2012 IEEE International. 2012.

14. Parks, K., P.Denholm, and T.Markel, Costs and Emissions Associated with Plug-In Hybrid Electric Vehicle Charging in the Xcel Energy Colorado Service Territory. 2007, National Renewable Energy Laboratory (NREL).

15. Hoog, J.d., K. Handberg, and R. Jegatheesan, Demonstrating Demand Management:How Intelligent EV Charging Can Benefit Everyone, in EVS27 International Battery, Hybrid and Fuel Cell Electric Vehicle Symposium 2013: Barcelona.

16. U.S. Energy Information Administration (EIA). Commercial Buildings Energy Consumption Survey (CBECS) Data 2012; Available from: http://www.eia.gov/consumption/commercial/data/2012/.

17. Hayter, S.J, and Torcellini, P.A., Advanced Energy Efficiency Design Strategies In Retail Buildings. 2000, National Renewable Energy Laboratory (NREL).

18. Sheppy, M., et al., Assessing and Reducing Plug and Process Loads in Retail Buildings. 2013, National Renewable Energy Laboratory (NREL).

19. Alhafi, Z., Calibrated energysimulations of potential energy savings in actual retail buildings, in Department of Architectural Engineering. 2014, The Pennsylvania State University.

20. Haves, P., B. Coffey, and S. Williams, Benchmarking and Equipment and Controls Assessment for a "Big Box" Retail Chain, in ACEEE Summer Study on Energy Efficiency in Buildings. 2008.

21. Field Implementation for Demand Response Strategies for Big Box Retail Stores 2008, Southern California Edison

22. Bonnema, E., M. Leach, and S. Pless, Technical Support Document: Development of the Advanced Energy Design Guide for Medium to Big Box Retail Buildings - 50\% Energy Savings 2013, National Renewable Energy Laboratory (NREL).

23. U.S. Department of Energy, Advanced Energy Design Guides. [cited 2016; Available from: http://energy.gov/eere/buildings/advanced-energy-design-guides.

24. U.S. Energy Information Admistration (EIA), Commercial buildings energy consumption survey (CBECS) Table B6. 2012; Available from: http://www.eia.gov/consumption/commercial/data/2012/index.cfm?view=characteristics\#b3.

25. U.S. Department of Energy, EnergyPlus Weather Data. [cited 2016; Available from: http://apps1.eere.energy.gov/buildings/energyplus/weatherdata_about.cfm.

26. Boyce, P. and P. Raynham, The SLL Lighting Handbook. 2009: The Society of Light and Lighting.

27. Discover Lighting An introduction to lighting basics. 2011. [cited 2016; Available from: http://www.ies.org/lighting/applications/interior-retail.cfm.

28. ENERGY STAR® Building Manual Facility Type: Retail. 2008. [cited 2016; Available from: https://www.energystar.gov/sites/default/files/buildings/tools/EPA_BUM_CH13_Retail.pdf.

29. EV Everywhere: Electric Vehicle Basics. [cited 2016; Available from: http://energy.gov/eere/eveverywhere/eveverywhere-electric-vehicle-basics.

30. SAE Charging Configurations and Ratings Terminology (SAE J1772). 2011; Available from: http://www.sae.org/smartgrid/chargingspeeds.pdf.

31. EV Everywhere: Vehicle Charging. [cited 2016; Available from: http://energy.gov/eere/eveverywhere/ev-everywherevehicle-charging.

32. 2017 Mitsubishi i-MiEV. [cited 2016; Available from: http://www.mitsubishicars.com/imiev\#trims.

33. 2017 Chevrolet Volt. [cited 2016; Available from: http://www.chevrolet.com/volt-electriccar.html?ppc=GOOGLE_700000001291955_71700000013736255_58700001139978712_p10148611530\&gclid=CMW b74CW5c8CFVBZhgodyi8KEg\&gclsrc=aw.ds\#content_chevrolet_northamerica_usa_nscwebsite_en_index_all-

vehicles-nav_cars_2017-volt_overview_jcr-content_cnt_legalpage_c1_disclaimers_disclaimer_c1_0.

34. Electric Vehicle Wiki [cited 2016; Available from: http://www.electricvehiclewiki.com/Nissan_Leaf.

35. Tesla Model S. [cited 2016; Available from: https://www.tesla.com/models.

36. 2017 Prius Prime. [cited 2016; Available from: http://www.toyota.com/priusprime/. 
37. Herron, D. EV DC Fast Charging standards - CHAdeMO, CCS, SAE Combo, Tesla Supercharger, etc. [cited 2016; Available from: http://longtailpipe.com/ebooks/green-transportation-guide-buying-owning-charging-plug-in-vehiclesof-all-kinds/electric-car-charging-advice-systems/ev-dc-fast-charging-standards-chademo-ccs-sae-combo-teslasupercharger-etc/.

38. Mogile Technologies, Electric Car Charging Guide. [cited 2016; Available from: https://chargehub.com/en/electric-carcharging-guide.html.

39. Tal, G., et al., Charging Behavior Impacts on Electric Vehicle Miles Travel: Who is Not Plugging in? 2013, Institute of Transportation Studies University of California.

40. Sehar, F., M. Pipattanasomporn, and S. Rahman, An Energy Management Model to Study Energy and Peak Power Savings from PV and Storage in Demand Responsive Buildings. Applied Energy, 2016.

41. Go Solar California. [cited 2016; Available from: http://www.gosolarcalifornia.org/equipment/.

42. Retail Lighting Guide. Holophane. [cited 2016; Available from: http://www.holophane.com/hlp_library/guides/HL- 450 2146.pdf.

43. Sehar, F., M. Pipattanasomporn, and S. Rahman, A peak-load reduction computing tool sensitive to commercial building environmental preferences. Applied Energy, 2016. 161: p. 279-289.

44. DiLaura, D.L., et al., The Lighting Handbook Tenth edition Reference and Application. 2011.

45. An Application Guide to Retail Lighting. CBMC Lighting Solutions. [cited 2016; Available from: http://retaillightinganddesign.com/wp-content/uploads/2013/10/CBMC-RETAIL-LIGHTING-GUIDE.pdf 